\title{
Differences in eating behaviours of secondary school children in Northern Ireland according to school type: the Young Person's Behaviour and Attitudes Survey
}

\author{
S.M. Wallace ${ }^{1}$, J.V. Woodside ${ }^{1}$, F. Kee ${ }^{1}$, P. Connolly ${ }^{2}$, L. Dunne ${ }^{2}$ and M.C. McKinley ${ }^{1}$ \\ ${ }^{1}$ Centre of Excellence for Public Health, School of Medicine, Dentistry and Biomedical Sciences, Queen's University \\ Belfast, Belfast, BT12 6BJ and \\ ${ }^{2}$ Centre of Excellence for Public Health, School of Social Sciences, Education and Social Work, Queen's University \\ Belfast, Belfast, BT12 6BJ
}

The prevalence of overweight and obesity in children and adolescents has become a major public health issue in Northern Ireland (NI). Previous studies have demonstrated differences in eating behaviours in this age group according to gender ${ }^{(1)}$; however much less research has been conducted in NI to investigate these differences according to whether pupils attend a secondary (no academic selection) or grammar school (exam required for entry).

The aim of the present study was to examine if self-reported food intake and breakfast consumption differed according to school type in the NI school-based Young Person's Behaviour and Attitudes Survey (YPBAS) ${ }^{(2)}$; the main aim of which is to gain a better understanding of the behaviour and lifestyle of young people. The survey (pupils $n=7076$, schools $n=75$ ) is representative according to factors such as school size and selection type. A 17-item food frequency questionnaire was used to assess dietary intake.

Statistically significant differences in self-reported dietary intake were observed according to school type, as shown in the table below; students in secondary schools were consuming significantly more portions per week of foods such as cakes, fizzy drinks, fried foods and crisps, and fewer portions of fruit and vegetables. A smaller proportion of students attending grammar schools reported never eating breakfast during the week $(11.3 \%$ versus $23.4 \%$ for grammar versus secondary respectively; $\mathrm{p}<0.001)$ and a larger proportion of grammar school students reported eating breakfast every day during the week when compared to students attending secondary schools (67.0\% versus $49.6 \%$ for grammar versus secondary respectively; $\mathrm{p}<0.001$ obtained from chi squared test).

\begin{tabular}{lcccccc}
\hline & \multicolumn{2}{c}{ Secondary } & & \multicolumn{2}{c}{ Grammar } & \\
\cline { 2 - 3 } Foods & Mean & $S D$ & & Mean & $S D$ & \\
\hline Chocolate & 7.113 & 4.685 & & 6.890 & 4.388 & 0.182 \\
Cake & 2.537 & 2.991 & & 2.145 & 2.343 & $\mathrm{p}<0.001$ \\
Fizzy drinks & 6.084 & 4.929 & & 4.229 & 4.164 & $\mathrm{p}<0.001$ \\
Diet drinks & 3.517 & 4.180 & & 2.366 & 3.218 & $\mathrm{p}<0.001$ \\
Crisps & 4.352 & 3.975 & & 2.974 & 2.799 & $\mathrm{p}<0.001$ \\
Chips & 3.573 & 3.047 & & 2.643 & 2.069 & $\mathrm{p}<0.001$ \\
Boiled potatoes & 3.256 & 2.830 & & 2.953 & 2.315 & 0.001 \\
Fried foods & 3.101 & 2.697 & 2.488 & 1.824 & $\mathrm{p}<0.001$ \\
Fruit & 6.409 & 4.700 & 7.974 & 4.859 & $\mathrm{p}<0.001$ \\
Vegetables & 5.221 & 4.215 & 6.549 & 4.530 & $\mathrm{p}<0.001$ \\
\hline
\end{tabular}

$\mathrm{P}$ values obtained by independent sample t test.

These results show a difference in the self-reported food intake in secondary versus grammar school pupils in NI, with secondary school pupils reporting a higher intake of foods high in fat and sugar. The next stage of this research will be to explore the determinants of these eating behaviours to better understand the potential reasons for these differences between school types.

1. Arganini C, Saba A, Comitato R, et al. (2012) Gender Differences in Food Choice and Dietary Intake in Modern Western Societies. https://www. intechopen.com/books/public-health-social-and-behavioral-health/gender-differences-in-food-choice-and-dietary-intake-in-modern-western-societies (accessed September 2016).

2. Northern Ireland Statistics and Research Agency (2015) Young Persons' Behaviour and Attitudes Survey, 2013. http://dx.doi.org/10.5255/ UKDA-SN-7624-1 (accessed September 2016). 